\title{
The introduction of the medicinal partner in direct-to-consumer advertising: Viagra's contribution to pharmaceutical fetishism and patient-as-consumer discourse in healthcare
}

\author{
Janelle Applequist \\ Zimmerman School of Advertising \& Mass Communications, University of South Florida, Tampa, FL, USA
}

\begin{abstract}
Pfizer, manufacturer of the erectile dysfunction prescription treatment Viagra, has been a staple in the pharmaceutical advertising arena since broadcast versions of such ads became legally permissible in the United States in 1997. Given that the patent for Viagra is soon set to expire, it is important that research take a look back in an attempt to contextualize the brand's place in shaping medicinal marketing culture. Of particular interest is the period beginning in 2014, when Viagra's most unconventional campaign yet began using a tactic that was the first of its kind for the pharmaceutical industry. By removing the actual consumer of the medication from these ads (males), Viagra has paved the way for pharmaceutical advertising to target the medicinal partner. This manuscript reviews the first use of the medicinal partner in the pharmaceutical advertising sector, conducting a textual analysis of Viagra's use of this mediated relationship. The medicinal partner is the pharmaceutical industry's attempt to target a patient's social circle in an effort to promote a discourse that suggests a medicinal remedy for a problem. This analysis describes how social meaning and relationships underlie the market transaction of obtaining a prescription, as has been previously established through the processes of medicalization and pharmaceutical fetishism. These advertisements create belief in the larger sense, meaning Pfizer is infiltrating upon the patient's process of choice and consumption of medicinal remedies. Viagra is simultaneously encouraging male consumers to celebrate the brand while using female ambassadors to influence the decision to request medicinal intervention.
\end{abstract}

\section{Introduction}

Ask your doctor about... is a phrase immediately rec-

Correspondence: Janelle Applequist, Zimmerman School of Advertising \& Mass Communications, University of South Florida, 4202 E. Fowler Ave. CIS 1040, Tampa, FL 33620, USA.

Tel.: 724.816.8840.

E-mail: applequist@usf.edu

Key words: Direct-to-consumer advertising; Medicinal partner; Pharmaceutical advertising; Textual analysis; Viagra.

Conflict of interest: the author declares no potential conflict of interest.

Funding: this work was supported, in part, by the University of South Florida Research \& Innovation Internal Awards Program under Grant No. 0115756 . The content is solely the responsibility of the author and does not necessarily represent the official views of the University of South Florida.

Received for publication: 19 June 2018.

Revision received: 2 August 2018.

Accepted for publication: 3 August 2018.

This work is licensed under a Creative Commons Attribution NonCommercial 4.0 License (CC BY-NC 4.0).

CCopyright J. Applequist, 2018

Licensee PAGEPress, Italy

Qualitative Research in Medicine \& Healthcare 2018; 2:65-72

doi:10.4081/qrmh.2018.7646 ognizable as synonymous with a direct-to-consumer (DTC) advertisement, signifying to media consumers that a better life is within reach if a prescription can be obtained. Although the pharmaceutical industry continues to claim that its broadcast advertisements serve as a form of health education for consumers, research has shown that these commercials seek to persuade consumers above providing informational value. ${ }^{1}$ With the prescription drug market now offering what seems like limitless options to consumers, and competing drugs entering the game, it has become more important than ever that pharmaceutical giants spend money on advertising their products. It also becomes important, however, to investigate the ways in which drugs are being commodified in an effort to further understand a patient's journey when deciding to ask their health care provider for a drug by name. The U.S. Department of Health and Human Services estimates that expenditures on prescription drugs will continue to increase at a faster rate than national health spending. In 2016, 16.7\% of U.S. health care spending went toward prescription drugs, equating to $\$ 457$ billion. ${ }^{2}$ On the whole, the advertising industry is decreasing its ad expenditures, yet big pharma has increased its budget to obtain more customers. Pharmaceutical companies spent $\$ 5.2$ billion on advertising alone in 2015, a substantial 19\% increase from ad spending in 2014. ${ }^{3}$ Broadcast ads have seen budgets increase more than $10 \%$ since 2011, causing an increase in the amount of ads to which viewers are exposed. ${ }^{3}$

Advertising culture, combined with pharmaceutical 
marketing, has created the ubiquitousness of DTC ads on television, but the evolution of this genre has created another category of consumer - the medicinal partner. This study introduces the concept of the medicinal partner's use in pharmaceutical advertising. The medicinal partner is the pharmaceutical industry's most recent attempt to increase sales, focusing on a patient's social circle to promote discourse that suggests a medicinal remedy for a problem. To date, Viagra has been the first pharmaceutical drug marketed using this tactic. The medicinal partner can then be defined as an individual in close social proximity to the consumer being targeted. This individual provides a role in a consumer's life that has influence and meaning for decision-making. To this end, Viagra serves as a reinvention of the standard pharmaceutical advertising formula, one that now adds a medicinal partner to the limited perceptions of health existent in the texts the industry promotes. Viagra and its use of the medicinal partner merits analysis because it is the first pharmaceutical brand known to employ such a tactic in the DTC advertising realm. While the social other (e.g. romantic partners, friends, family members, influential peer groups, etc.) comprises a category often used in advertising for other product categories, the use of this group in the pharmaceutical sector presents an important area for analysis, as prescription drugs carry significantly more risk than other items being sold by advertisers.

\section{Medicalization, pharmaceuticalization, and pharmaceutical fetishism}

While sociological critiques regarding the influence of media systems have been documented, ${ }^{4}$ there is more research to be done concerning the more specific domain of health and medicinal remedies.

In 1994, Deborah Lupton published a seminal piece in Health Communication arguing for more critical health communication research, drawing attention to the relationship between power and control in forming ideologically-accepted notions of health problems and solutions in society. A main tenant of this argument included the necessity of patients having more active and equal roles in dyadic encounters with their physicians, eliminating the hierarchical structure of medicinal encounters. ${ }^{5}$ While necessary and commendable in its form, Lupton's argument focused on the interpersonal forms of communication, emphasizing the discourse used in medical settings, often to show the ways in which the social concerns of patients related to their health status are repeatedly marginalized and ignored by practitioners. ${ }^{6}$ Still, further consideration should be given for an emphasis on mediated forms of sociological influence (i.e. advertisements) to show how such forms of communication influence sociological constructions of what it means to be healthy or ill, and even at times, to be happy or sad. Health promotion efforts inevitably influence the ways in which various publics know of and understand various health ailments and treatment options. The mass media serve as agents of modernization, exposing individuals to health information, ways of living, and linear models of proposed action seen throughout various health campaigns that are aimed at behavior change. ${ }^{7}$

It is important that the fields of communication and mass communications investigate media-based efforts to influence health care, as the mass media are themselves tools of modernization built on capitalist ideology, which inherently introduce new risks to audiences. ${ }^{8}$ For example, the addition of pharmaceuticals to the health care marketplace offers solutions for individuals in that their health ailments may be lessened or more easily managed, however, this introduction inevitably creates a space whereby patients have the potential to suffer side effects associated with pharmaceuticals, possibly having a potentially negative impact. Scholarship must acknowledge the ways in which knowledge production intersects with power, ideology, and hegemony within the realm of health advertising. ${ }^{89}$

Advertising is a media system that influences sociological meaning and collective understanding of various issues. ${ }^{10}$ Advertisements tap into not necessarily what people need, but what they dream about - channeling emotions, experiences, and images that reflect our deepest desires in a way that, for a moment, makes us feel as if we really can have it all. Advertising for products related to health, then, serves as a fundamental commodity-image system where particular visions of what would provide sources of satisfaction become measuring sticks for our success as psychological, social, and physical beings. ${ }^{10,11}$

Relevant to the discussion of advertising's influence on sociological conceptions of health, medicalization is the process whereby something is made or turned into a medical matter. ${ }^{12}$ Pharmaceuticalization, then, is the process whereby prescription drugs gain and maintain a significant presence throughout society. ${ }^{13}$ Research has relied upon the term to indicate society's over-reliance on prescription drugs. Pharmaceuticalization also refers to the blurring of the boundaries between what is medical treatment versus enhancement, transforming human problems into medicinally-appropriate issues. ${ }^{14}$ Therefore, medicalization creates what we in society understand as an illness or ailment, and pharmaceuticalization offers a prescription drug as the best option for treatment. The final step in the process is defined as pharmaceutical fetishism.

Pharmaceutical fetishism is a theoretical lens describing the celebratory process of a medicinal remedy as the ultimate option for better health, often at the expense of ignoring other treatment options or lifestyle changes, aligned with romanticized portrayals of the better life one will have as a result of receiving a prescription drug. The process of pharmaceutical fetishism can be described as: the commodification of brand-name pharmaceutical drugs, which, via advertising and promotional cultures, ignore large-scale production and for-profit motives of big pharma while simultaneously reiterating a brand discourse 
that offers individuals additionally constructed meanings that promote medicine as a cultural authority in health care and prescription drugs as having the capacity to solve individual problems beyond those for which a medicine is scientifically intended. ${ }^{10}$

Pharmaceutical fetishism most often occurs via advertising, with prescription drug commercials featuring patient scenarios with positive emotional appeals, often emphasizing better romantic relationships, more cohesive and happy family units, more fulfilling friendships, and increased wealth in addition to having better health. ${ }^{1} \mathrm{~A}$ closer look at the introduction of Viagra to the pharmaceutical marketplace helps to deconstruct the process of pharmaceutical fetishism and the broader processes of social structure, thereby allowing for a more detailed looked at the major themes present in Viagra's most recent advertisements.

\section{Materials and Methods}

This research utilizes textual analysis to review Viagra's most recent stream of advertisements. This method, alongside the aforementioned historical journey of the brand to provide further context, provides a holistic analysis of the drug's advertisements over time, leading up to the deconstruction of its most recent campaign to decode its contextual meanings. Reliant upon Gitlin's interpretation of textual analysis, this study emphasizes how format, setting, character type, and solution are presented in ways that help in identifying embedded hegemonic processes focused on masculinity, femininity, and consumption. ${ }^{15}$ Older ads associated with Viagra and its advertising history were collected from available online resources (e.g. YouTube, iSpottv, etc.), with a total of 15 ads downloaded and analyzed for themes indicative of the brand's creative shift over time. The most recent Viagra campaign constructing the bulk of this analysis was collected via SnapStream software, a television recording program that allows for the search of specific content recorded via transcriptions available. This portion of data collection was conducted for a 12-week period, equating to 90 days of programming across the four major broadcast networks (ABC, CBS, $\mathrm{NBC}$, and FOX) during primetime viewing hours. In total, 8 different ad versions for Viagra were featured during this recording period, accounting for a total of 72 times that a Viagra ad aired across the four networks during the 12week collection period. Following Stern's framework for conducting a textual analysis, this study systematically analyzed the ads by identifying textual elements, investigating the construction of provisional meaning embedded in texts, and subsequently deconstructed sociological meaning. ${ }^{16} \mathrm{An}$ analysis of major themes present in the older ads is also presented in chronological order to describe Viagra's shift in image over time, whereas the analysis of the medicinal partner being used in more recent campaigns is presented via a more detailed deconstruction.
Finally, a textual analysis of the newest stream of Viagra ads shows the ways in which the drug's marketing strategy has shifted to include a new (and much more profitable) demographic. By relying upon a grounded theory approach in identifying major themes present in each $\mathrm{ad}$, this research utilized a constant-comparative method in analysis to determine primary themes being conveyed by these texts. The manufacturer now focuses on targeting a consumer other than the individual taking the medication. The focus on the medicinal partner merits analysis, as the pharmaceutical industry's advertising tactic may be blurring the boundaries of bodily authority, moving toward a model that could permit another (e.g. the sexual partner) to have increased influence over the decision one makes about their own body. A textual analysis of these latest ads shows how themes centered on a faux source of female-empowerment is repositioning the brand.

\section{Results and Discussion}

\section{Viagra's advertising evolution}

Erectile dysfunction (ED) can affect men under the age of 40 , but occurs at higher rates for aging populations, with rates increasing in correlation with one's age (e.g. $40 \%$ of men in their $40 \mathrm{~s}, 50 \%$ of men in their $50 \mathrm{~s}$, etc. .). ${ }^{17}$ The aging population serves as the demographic most susceptible to developing ED. Couple this with the fact that more than half of all broadcast television viewers are 54 and older, and it is clear that Pfizer has had a recipe for a lucrative combination since its creation. ${ }^{18}$

The story of Viagra is itself a tale of pharmaceuticalization, as a 1992 conference officially renamed impotence, a psychogenic problem, to the slang term of $E D$, a biogenic ailment. ${ }^{19}$ It was not until Viagra's marketing launch that erectile dysfunction became referred to as ED, promoting a type of cultural slang to signify the topic of impotence in a way that made it seem more approachable to the public..$^{20}$ First approved by the Food and Drug Administration (FDA) in the United States in March 1998, Viagra was marketed primarily to older men for ED associated with prostate cancer, diabetes, and other medical conditions. Beginning its first marketing campaign with Senator Bob Dole as a spokesman was fitting, as Pfizer initially wanted to rename impotence to ED in social circles, focusing first on the most common demographic associated with the term, aging men. ${ }^{20}$ It soon became apparent, however, that an aging population coupled with larger sociological concerns of sexual performance led for a much broader audience. Viagra became known not only as the remedy for ED, the medicalized term, but as a product that could help those not even experiencing ED. The pill became associated with something that could give men that extra edge in the bedroom..$^{20}$ The recreational use of Viagra permitted Pfizer to begin marketing the drug as something capable of addressing male insecurities for 
recreational purposes without having to directly connect men with impotence - the implication here being that Viagra wasn't treating a problem, but rather, it was enhancing a man's ability to endure, perform, and be powerful. Viagra wasn't there to fix a broken man, but rather, acted as a tool to help men be better versions of themselves.

Pfizer's first television advertisement for Viagra in 1998 got the attention of older men, the initial target audience. It featured a stoic, confident Bob Dole, talking to the camera as he says:

Courage - something shared by countless Americans. Those who've risked their lives. Those who battle serious illness. When I was diagnosed with prostate cancer, I was primarily concerned with ridding myself of the cancer, but secondly, I was concerned about possible post-operative side effects, like erectile dysfunction, ED, often called impotence.

Though he never mentions Viagra by name, the ad makes the association for viewers that impotence is now being referred to as ED, a more legitimate-sounding medical condition therefore requiring some type of medical intervention. As Pfizer's audience for Viagra became broader, their advertising techniques began to reflect this change, at times leading the drug manufacturer to be reprimanded by the FDA. In 2004, the Wild Thing television ad aired, featuring a husband and wife window shopping along a street. The narrator asks: remember that guy who used to be called 'Wild Thing'? The guy who wanted to spend the entire honeymoon indoors? Remember the one who couldn't resist a little mischief? Yeah, that guy. He's back. As the narrator is discussing the man's comeback, the husband stops his wife to look at a black lingerie ensemble featured on a mannequin in a shopping window. She blushes, and he gives an ornery smile, as two triangular blue Viagra tablets appear behind his head to simulate devil's horns. The ad names the drug, yet never reveals the condition the medication treats or its possible side effects. This landed Pfizer in hot water, with the FDA sending a warning letter requiring that the ad be pulled. Not only did the FDA find that the ad failed to uphold the requirements of a product claim ad, but that it, along with other campaigns, claim that Viagra will provide a return to a previous level of sexual desire and activity. The FDA is not aware of substantial evidence or substantial clinical experience demonstrating this benefit for patients who take Viagra. ${ }^{21}$ This is telling because it shows that Pfizer has been warned before about making false promises to individuals through its advertising.

From 2010 to 2012, Pfizer refocused its advertisements using a lens of hyper-masculinity. A different approach from the colorful, bubbly ads that came before them, these versions featured dark, muted colors of older, albeit very attractive, men in isolated settings. Each ad featured one man, outdoors in some capacity, with him focusing on overcoming a challenge in a hyper-masculine fashion. Using horses to remove a trailer stuck in the mud, using one's muscles while commercial fishing, and starting a bonfire using only what's available on the shore of a beach are scenarios presented. This is the age of ... is the slogan, followed by phrases that vary for each ad, including knowing how to get things done, knowing how to make things happen, and knowing what you're made of. The ads go on to reiterate that twenty million men have already taken Viagra, reinforcing the bandwagon approach necessary to be a real man when faced with a medical ailment. Prior to Pfizer's most recent campaign for Viagra, all ads at some point featured the sexual partner, who was always female, and none of these characters ever had a speaking role. Instead, the women were included in ways that positioned them as being in awe of the masculinity, vibrancy, and romance the men were exhibiting thanks to Viagra.

\section{A textual analysis of Pfizer's use of advertising as a vehicle for targeting the medicinal partner}

Beginning in 2014, Pfizer changed the predictable formula of its ads for the ED medication, shifting the focus from the male to the female, featuring mature, attractive women that talk directly to the camera (with their male counterparts nowhere to be seen or heard). Pfizer's latest advertisements each feature a monologue delivered by one woman in each version. She is alone, in an intimate setting, talking directly to the camera. For a product that is only consumable by men, it feels odd the first time you watch any of these ads, as no men are featured in these spots. First airing in 2014, the campaign uses a solo female character as the focal point for each ad.

This textual analysis of Viagra advertisements found two primary themes: i) the male partner as dominant and hypersexualized, and ii) the female partner as evolved from submissiveness toward an increased sexual appetite still dependent upon that of the male partner. In both cases, the role of the medicinal partner is magnified, yet the newest Viagra campaigns featuring only women enhance this role in a way that eliminates the man from the conversation altogether. Interestingly, these texts are presented in a way that revises the consideration of a medical diagnosis into a conversation that largely emphasizes sex, whereby the consumer of the ad is so inundated by the talk of relationships, sex, and romance that, at times, it becomes easy to forget the fact that a health condition is the basis for the ad. This adds to existent concerns regarding the culture of the pharmaceutical drug industry, where brand names are emphasized in ways that often trump education on medical ailments. The pharmaceutical fetishism, then, becomes the ways in which Viagra and its brand identity become the first solution for ED, in a way that celebrates the drug as a cultural authority and relationship solution.

The women featured in Pfizer's newest ad campaign fit the bill for advertising's ideal version of femininity they are attractive, deferential, unaggressive, emotional, 
nurturing, and concerned with their relationships. ${ }^{22}$ In all versions, the woman is speaking directly to the camera while lying on her bed, as if she is having an intimate conversation with a man who may be struggling with his impotence (Figure 1). Each woman is wearing a sleeveless blue dress, indicative of Viagra's tag line as the little blue pill, and the delivery of her message is done in a way that mimics more of a gentle conversation that is the push a man may need to discuss the medication (not the condition) with his doctor.

Their physical presentation is impeccable, with each woman being a portrayal of what has been reaffirmed as the perfect woman via the male gaze in consumer culture. Each woman is tall, thin, beautiful, and confident. They are clearly successful, as they are shown in environments reserved for the elite. Upper class homes with ocean views are portrayed, with bedrooms decorated with little except for the focal point that is the bed. In one ad version (Figure 2), the character enters her bedroom holding her purse, clearly just arriving back home after an evening out, as she seductively states:

Going out for date night with your man is nice, but I think women would agree - snuggling up after (as she lays down) is kind of nice, too. But here's the thing (she looks down). About half of men over 40 have some degree of erectile dysfunction. Well (looking back at camera), Viagra helps guys with ED get, and keep, an erection.

As the ad continues with a narrator describing the legally required risk information, the woman is shown sitting in front of her vanity and getting ready for bed. She pulls her hair down and removes her earrings. As her silhouette is shown walking behind curtains in her home, she makes direct eye contact with the camera and gives a sexy grin. The ad ends with her laying across the bed, placing her hands underneath her chin, and smiling while saying ask your doctor about Viagra.

The character in this ad is of mixed-race, presumably including Caucasian and African American roots. When

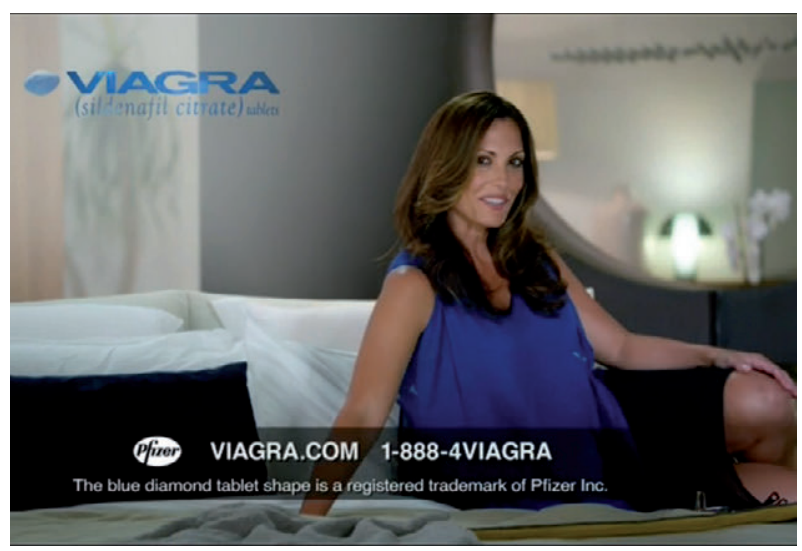

Figure 1. A broadcast advertisement for Viagra, featuring a female lead character, aired 2016-present. this Viagra campaign does use a woman of minority status in its ads, it does so in a way that is seemingly promoting racial (and sexual) equality, yet obviously construed via Western reinterpretations of what it means to be African American or Asian. Being a minority character in these Viagra ads means that the character is not connected with their cultural identity, as they are fully assimilated in and non-distinguishable from white culture.

Beyond the product being sold in these ads, Pfizer is also reiterating a model of white consumption, where minorities are caricatured in ways that exotify their being as made for sexual subservience to men. ${ }^{23}$ Furthermore, the campaign delivers messages insinuating these women are eager to engage in sex with their partners, yet does so in a way that presents them as innocent and pure. The physical characteristics of the minority characters combined with their outward dispositions further fulfil the exotic stereotype seen in advertising so many times before. ${ }^{23}$

These ads are constructed in a way that targets both men and women (if we are assuming that heteronormative, heterosexual sexual relationships are the only ones that exist, which is certainly not true, but seems to be a key component of Pfizer's marketing scheme). These ads rely on a female to push a product only directly consumable by men, but does so in a way that alludes to the sexual abilities a man can gain, yet this is still to the woman's benefit. Therefore, depending on which gender is consuming the ad, it is read and understood as being made just for you. If you are a man, your sex life will improve and you get to see an attractive woman selling you the idea. If a woman, you get to partake in the insidiousness of fixing your partner, seeing how your femininity and sex appeal can, like the main character, be the persuasive argument needed to get your partner to ask their doctor about Viagra.

By encouraging men to ask their doctors about Viagra, Pfizer is simultaneously encouraging male consumers to celebrate the brand and first and foremost consider the

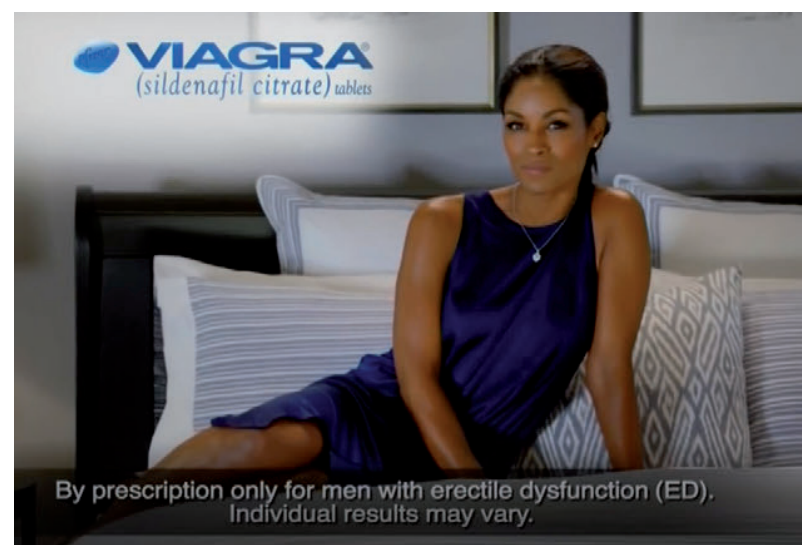

Figure 2. A second broadcast advertisement for Viagra, aired 2016-present. 
positive influence the small blue pill could have on their sexuality. Doing so requires that the serious side effects possible while taking this medication be considered an afterthought, whereby physical complications (including sudden vision or hearing loss and permanent damage to the penis) are deemed less important than the promise that is always seen in consumer culture - side effects become mere sacrifices made in the name of having a happier life. But it is by using a female ambassador for the brand that Pfizer is, for the first time, using the relational counterpart to serve a dual purpose - position a woman as having the ability to literally change her man for her own gain while providing a false autonomy of liberated sexuality. This sexuality, though, is presented through a false lens that favors heteronormative assumptions of what it means to be male or female.

The sociological construct of hegemonic masculinity argues that men's multiple, performed masculinities act along a continuum that exist to reinforce gender boundaries. ${ }^{24}$ This campaign creates a scenario where a man is seen through the eyes of his female partner - the implication being that the men being talked about are strong, attractive, and righteous, yet; the ads simultaneously present a rarer form of hegemonic masculinity that positions men as being attentive to the emotional and physical needs of the women they care about. ${ }^{25}$ The irony here is that the man is never physically present in the ads, but Pfizer conveys this information without having him in the scene. The man is positioned as the redeemer, or the one in the relationship that can fix the problem at hand. The perfect man is constructed via these ads, and is one that is customizable by design because he is never present on the screen. He is the man a male viewer sees himself as becoming, and the man a female viewer dreams about having.

The female characters are presented via the male gaze, positioning each through a frame of what consumer culture tells us regarding how the ideal woman should look, speak, and act. Historically, this is nothing new, as commercial programming has long told women to strive for a prescribed version of perfection, including the need for a perfect body, flawless appearance, and successful career. ${ }^{26}$ What is new is Pfizer's narrative of a female improving herself by influencing her partner's sexuality in a way that crosses boundaries not available when selling other product categories. The false autonomy present here positions the woman as having the power and prowess to convince men to get a prescription from their doctor. Different than other products that could be advertised and purchased between two romantic partners, this category invites a third party into the bedroom - the physician that must write the prescription. This creates a relationship flow between partner 1, partner 2, and the physician, which symbolizes the very goal of advertising. Advertising does not just sell products, but if successful, creates an interactive flow between marketing institutions and the cultural world [where] meaning is produced through a culturally deter- mined and socially mediated process which is shared and negotiated between producers and consumers. ${ }^{27}$ Therefore, Pfizer has done more than tap into a new demographic in using women in its latest advertising campaigns. It has brought women into the conversation via veiled portrayals that rely upon already-prescribed cultural aspects of sexuality and gender. The women in the ads are shown as entirely fulfilled as long as they can have (penetrative) sex with their partner, stripping away any ability to consider feelings, experiences, or context of relationships. Instead, women are presented as beings easy to master by the opposite sex - keep her pleased in the bedroom, and she will have nothing to complain about. Using a limited version of what constitutes sexuality (penetrative intercourse between a male and female), the ads clearly position the women via the male gaze, meaning they are portrayed in a hypersexualized manner consistent with consumer culture, presenting versions of women as men want to see them. Men watch women and women watch men watching women. ${ }^{28}$

This analysis provides an example for understanding how social meaning and relationships underlie the market transaction of obtaining a prescription drug. These particular advertisements may be creating belief in the larger sense, meaning Pfizer is influencing the medicinal partner to become a focal point in a patient's process of choice regarding medicinal remedies, while also making a strong statement about heterosexual relationships and individual romantic identity. ${ }^{29}$ The irony here, of course, is that receiving a prescription for Viagra will not be the cure-all for a relationship. Viagra cannot fix a broken relationship or create the perfect sexual encounter, yet its ads show us that it can.

\section{Conclusions}

This study provided the first identification and deconstruction of a medicinal partner's role in pharmaceutical advertising, meaning that it is likely the pharmaceutical industry will use this tactic again in the future. This merits future analysis, as the medicinal partner will play an increasingly important role in terms of media consumption and patients asking their doctors about name brand prescription drugs. Above even medicine, as agentic beings we hold authority over our own bodies, ultimately having the power to decide which treatment options we will consider and adhere to. However, the success of Viagra, financially and culturally, is evidence of Pfizer's larger power over health discourse.

The limitations of this study include its analysis of broadcast advertisements, not considering the content of Viagra advertisements featured via print (e.g. magazine advertisements) or online. Additionally, this study is based on advertisements in the United States, which raises the question of whether such promotions are being used in non-U.S. markets for other health care categories. This 
particular area presents an opportunity for future analysis, especially in comparison to New Zealand, the only other industrialized nation in the world that permits such advertising of the pharmaceutical sector.

The pharmaceutical fetishism inherent in the most recent stream of Viagra ads is not only the implication that one will have sex. It is the suggestion that one will have better sex that gets the consumer's attention. Viagra acts as a form of life enhancement so very indicative of the pharmaceutical industry - the medication will not change who you are, but it will make you a better version of yourself, meaning a better life is well within reach. Consumption is at the heart of this ad campaign, as it is positioned to reflect a woman's desire to obtain sex with her partner, and plays on the inadequacy a man may feel for not being able to engage in intimate relations with another. The pharmaceutical industry itself prides itself on consumption. In the literal sense, the more pills American are prescribed, the more money is made. In other ways, the theme of consumption aids in perpetuating the alreadyexistent discourse of medicinal authority in the United States - prescriptions are the first option we go to when faced with a medical ailment or condition, assuming a type of cultural significance in that the act of taking a pill becomes positioned as a form of proactivity by the patient. Perhaps most important from this analysis is the role of the medicinal partner introduced to the process of pharmaceutical fetishism. While advertising has previously utilized the romantic partner as a persuasive technique, this marks the first time the advertisement solely relies upon that individual. The individual that would actually consume this medication is nowhere to be seen. In ads for other ED medications, for example (e.g. Cialis), the medicinal partner is a feature of the patient's story and journey. In the case of Viagra, a new format has been introduced that effectively removes the patient altogether, yet does so in a way that seems harmless. However, upon further inspection, this new persuasive technique is concerning, as this shift signifies a potential re-organization of the patient's authority in asking their doctor about a medication. More than just a form of suggestive sale made by one's romantic partner, this presents more questions than answers in terms of how this can impact the discourse of health care that is already over-commercialized in favor of profit in the United States. Additionally, from the alternative viewpoint, these ads are equally problematic in regard to the poorly-executed portrayals of postfeminist female partners featured. At face value, these women are presented as empowered, having the ability to not only fix their partner's ED, but they also are given the space to freely discuss their sexuality. Upon further inspection, however, this is a form of faux-empowerment, as it focuses on sexuality in a way that serves to please the male partner, further embedding ideas of what is means to be a normal female sexual partner, perpetuating an ideology that assumes a sexual deficiency is something that must be fixed via performative gender practices. ${ }^{30}$

The genre of pharmaceutical advertisements have strongly influenced our health care, changing the ways in which we discuss our treatment options with providers, and no doubt serves a capitalist agenda. This form of commercial culture has intersected some of our most vulnerable, private moments - our conversations with our doctor, changing the course of these conversations in a way that is centered on a product to be bought and sold. While the need for pharmaceuticals is paramount, the cultural shift from patient to consumer raises concerns regarding the quality of our health care system. The focus of pharmaceutical advertising should not be on revenue in terms of success measurement - we already know the market effect of this product category. It is arguably too lucrative, too indoctrinated into our media system, to ever go away. The more pressing matter is the consideration of the cultural impact of these ads. An advertisement tells a story, and Pfizer has created a whole new book for us to begin reading with its latest campaign.

\section{References}

1. Applequist J, Gerard Ball J. An updated analysis of directto-consumer television advertisements for prescription drugs. Ann Fam Med 2018;16:211-6.

2. Department of Health and Human Services. Observations on trends in prescription drug spending, ASPE Form OMB No. 0990-0379. Available from: https://aspe.hhs.gov/pdf-report/observations-trends-prescription-drug-spending. Accessed 2018 May 14.

3. Kantar Media. U.S. measured ad expenditures declined $3.9 \%$ in Q3 2015 to $\$ 36$ billion. Available from: http://www.kantarmedia.com/us/newsroom/pressreleases/us-measured-ad-expenditures-declined-3-9-q32015-36-billion. Accessed 2018 May 2.

4. Adorno T, Horkheimer M. Dialectic of enlightenment. New York, NY: Continuum; 1989.

5. Lupton D. Toward the development of a critical health communication praxis. Health Commun 1994;6:55-67.

6. Sharf BF, Street RL Jr. The patient as central construct: shifting the emphasis. Health Commun 1997;1:1-11.

7. Hallin DC, Briggs CL. Transcending the medical/media opposition in research on news coverage of health and medicine. Media Cult Soc 2015;37:85-100.

8. Jyotti Dutta M, de Souza R. The past, present, and future of health development campaigns: reflexivity and the criticalcultural approach. Health Commun 2008;23:326-39.

9. Kline NM. Popular media and health: images, effects and institutions. In: Thompson T, Dorsey KI, Miller R, eds. Handbook of health communication. Mahwah, NJ: Lawrence Erlbaum; 2003. pp 557-81.

10. Applequist J. Broadcast pharmaceutical advertising in the United States: prime time pill pushers. Lanham, MD: Lexington; 2016.

11. Jhally S. Image-based culture: advertising and consumer culture. In: Dines G, Humez JM, eds. Gender, race, and class in the media: a critical reader. Thousand Oaks, CA: Sage; 2011. pp 199-203. 
12. Conrad P. The medicalization of society: on the transformation of human conditions into treatable disorders. Baltimore, MD: Johns Hopkins University Press; 2007.

13. Clarke AE, Shim JK, Mamo L, et al. Technoscientific transformation of health, illness, and US biomedicine. Am Sociol Rev 2003;68:161-94.

14. Williams SJ, Seale C, Boden S, et al. Waking up to sleepiness: modafinil, the media and the pharmaceuticalisation of every day/night life. Sociol Health Illn 2009;30:839-55.

15. Gitlin T. Prime time ideology: the hegemonic process in television entertainment. Soc Probl 1979;26:251-266.

16. Stern BB. Textual analysis in advertising research: construction and deconstruction of meanings. J Advert 1996;25:61-73.

17. Feldman HA, Goldstein I, Hatzichristou DG, et al. Impotence and its medical and psychosocial correlates: results of the Massachusetts male aging study. J Urol 1994;151:54-61.

18. Thompson D. Half of broadcast TV viewers are 54 and older - yikes. The Atlantic. 2014 Available from: https://www.theatlantic.com/busin ess/archive/2014/03/half-of-broadcasttv-viewers-are-54-and-older-yikes/284256/. Accessed 2018 May 30.

19. Conrad P, Leiter V. From Lydia Pinkham to Queen Levitra: direct-to-consumer advertising and medicalization. Sociol Health Illn 2009;30:825-38.

20. Newman R. "Let's just say it works for me": Rafael Palmeiro, Major League Baseball, and the marketing of Vi- agra. NINE: A J Baseball Hist Cult 2006;14:1-14.

21. Hensley S, Vranica S. FDA tells Pfizer to pull Viagra ads about 'wild thing'. Wall Street Journal. 2004 16. Available from: https://www.wsj.com/articles/SB11005566598127459. Accessed 2018 April 29.

22. Wood J. Gendered lives: communication, gender, and culture. 3rd ed. Belmont, CA: Wadsworth Publishing; 1999.

23. Balaji M, Worawongs T. The new Suzie Wong: normative assumptions of white male and Asian female relationships. Commun Cult Critique 2010;3:224-41.

24. Butler J. Performative acts and gender constitution: an essay in phenomenology and feminist theory. Theatre $J$ 1988;40:519-31.

25. Henson L, Parameswaran RE. Getting real with "tell it like it is" talk therapy: hegemonic masculinity and the Dr. Phil show. Commun Cult Critique 2008;1:287-310.

26. Faludi S. Backlash: the undeclared war against America's women. New York, NY: Doubleday; 1991.

27. Tharp M, Scott LM. The role of marketing processes in creating cultural meaning. J Macromarketing 1990;48:47-60.

28. Berger J. Ways of seeing. London: Penguin; 1972.

29. Schudson M. Advertising as capitalist realism. In: Turow J, McAllister MP, eds. The advertising and consumer culture reader. New York, NY: Routledge; 2009. pp 237-255.

30. Bedor E. It's not you, it's your (old) vagina: osphena's articulation of sexual dysfunction. Sex Cult 2016;20:38-55. 